\title{
The Write Stuff: The Development of a Medical Writing Pharmacy Residency Elective
}

Emily K. Frederick PharmD ${ }^{1}$; Emma C. Palmer, PharmD²; Emily A. O'Reilly, PharmD ${ }^{3}$; Amanda K. Kuszmaul, PharmD Cathy Spencer, PharmD

${ }^{1}$ Sullivan University College of Pharmacy and Health Sciences; ${ }^{2}$ University of Cincinnati James L. Winkle College of Pharmacy;

${ }^{3}$ University of Louisville Hospital Specialty Pharmacy; ${ }^{4}$ Norton Hospital

\section{ABSTRACT:}

The Problem: Effective medical writing requires a mastery of many skills including those of data interpretation, literature evaluation, written communication, and leadership. A number of these skills are considered educational goals and objectives for residents by the American Society of Health-System Pharmacists, yet preceptors and residents oftentimes face challenges in gaining competency, confidence, and success in medical writing.

Innovation: A structured yet individualized plan for medical writing, including idea creation, peer reviewing, manuscript preparation, and team management for post-graduate year two pharmacy residents was implemented as an elective learning experience.

Results: Feedback from residents participating in the elective was positive. Each of the two residents who participated produced a manuscript that was subsequently published.

Conclusion: Though data is limited by number of residents that have completed this learning experience, this longitudinally designed elective has potential benefits and barriers to execution that should be considered, but may be an excellent opportunity to develop critical skills in scholarly endeavors for residents and preceptors alike.

Keywords: pharmacy, residency training, publications, medical writing

\section{Description of Problem}

Publish or perish. A ubiquitous statement heard throughout academia. Though this is a phrase that likely originated in the realm of tenure-hopeful professors in large academic institutions, the pressure, meaningfulness, and opportunity of publication is more and more relevant for pharmacists in clinical and academic realms alike. ${ }^{1}$ Medical writing and research skills are a required competency for pharmacists completing post-graduate year-two (PGY-2) residency programs $^{2}$ and residents benefit from these experiences professionally by growing their confidence, skills, and scholarly body of work. At the heart of medical writing the medical, pharmacy, and learning communities benefit from the dissemination of new knowledge, different perspectives, and experience. Residents that successfully publish their research from training are significantly likely to publish again within their early careers. ${ }^{3}$ Despite these standards and benefits of medical writing experience and success, residents and residency program directors (RPDs) frequently find themselves struggling with providing robust writing experience and successes, with reported publication rates of resident projects ranging from 1.8 - $15 \%$ and a median time to publication of 24 months. ${ }^{4-6}$

A significant reported obstacle to publication is time, particularly completion of a publishable project within a year.

Corresponding author: Emily Frederick, PharmD, BCPS Associate Professor, Clinical and Administrative Sciences Sullivan University College of Pharmacy and Health Sciences 2100 Gardiner Lane, Louisville, KY 40205

Phone: (502) 413 - 8989; Email: efrederick@sullivan.edu
Other commonly cited barriers include difficulty in understanding the publication process and study design limitations..$^{5-7}$ Other issues, such as resident motivation, preceptor writing expertise, research project approval processes, and communication with preceptors after residency completion, may also pose challenges to success in scholarship. A study of PGY-2 critical care graduate perceptions associated with publication success found that research mentor experience and perceived value of publication to the employer were associated with publishing a project versus not. ${ }^{8}$

There is some evidence to suggest that a targeted effort and approach to writing and publishing in a resident population can be successful. Clemmons and colleagues have reported on successfully increasing resident authorship rates after implementation of a formalized writing project as a part of $P G Y 1$ and $P G Y 2$ residencies, though the intervention was a mix of additional writing projects and primary research writing projects versus a dedicated experience within the residency schedule. $^{9}$ Given the aforementioned barriers and ripe opportunity for resident learning and scholarly contribution, an elective idea was generated, and an experience fashioned. To promote scholarship and publication, this article aims to describe a medical writing longitudinal elective designed for PGY-2 ambulatory care pharmacy residents that is primarily completed during the residency program.

\section{Description of the Innovation}

At the time of this program's initiation, the residency program director was seeking to expand longitudinal elective experiences, including a venue to enhance the resident's scholarly work outside of the required residency research and manuscript. Residents are often involved in other significant 
projects, clinical contributions, designing and executing new services, etc. and this elective experience also provided the opportunity and support to write about these efforts.

Conception of this new elective included securing preceptors and building a new syllabus and schedule as a team. The American Society of Health-System (ASHP) PGY-2 ambulatory care educational goals and objectives selected for teaching and/or evaluation in this elective focused on project development and execution, written communication and leadership, and teamwork skills (Table 1 ).

\section{Description and Design of Elective}

This elective was to be selected at the beginning of the resident's year-long residency cycle and no specific criteria were necessary to complete this experience other than interest. Participating residents were scheduled to dedicate one afternoon block (approximately four hours) per week for four months. During these afternoons, the resident did not have patient care responsibilities and time was protected for this experience. This elective was scheduled in the first half of the residency to increase the likelihood of project completion and accepted publication prior to graduation. Required activities for the elective involved conducting a peer review and a scholarly project by the end of month four, with the understanding that further revisions and resubmissions may be required beyond the initial rotation. The recommended project was conducting a systematic review based on an area of interest or focus for the resident's year; however, other projects were acceptable including case report/case series manuscripts or narrative reviews.

The RPD identified two junior to mid-level academicians at a partner institution with residency precepting experience to serve as co-preceptors for this experience and mentorship of the residents. These individuals had some publishing experience, but identified that additional scholarly opportunities were of interest to them. Additionally, the partnership served to strengthen the relationship between the school and the clinical practice site institution.

During the elective, pertinent resources were reviewed and provided to the resident, based on their project. If applicable based on project selection, a guide on peer reviewing was provided to each resident, as well as of the statement on Preferred Reporting Items for Systematic Reviews and MetaAnalyses (PRISMA). ${ }^{10}$ To assist in the data filtering and collation, review, and collaboration necessary for a systematic review, an online software tool, Rayyan (Qatar Computing Research Institute (Data Analytics), Doha, Qatar), was utilized. This software facilitates individual blinded application of inclusion/exclusion criteria and coding by multiple reviewers, as well as a platform for article organization. ${ }^{11}$
The schedule for the elective consisted of 16 core weeks of work and/or meetings (Table 2). During the first week of the experience, the syllabus was discussed, and individual resident goals and objectives were defined. With these in mind, ideas for projects were discussed and the resident spent independent time researching and considering ideas prior to making a final decision. Resources were discussed based on the identified goals, project selected, and previous experience of the resident. There were at least six meetings with one or more preceptors throughout the experience, with general expected times to meet provided to the resident at the beginning of the experience, but changed depending on their needs. It was expected that the majority of the resident's time would be spent independently working. During those times, however, preceptors might be assisting in work, such as article and data review between face-to-face meetings. It was expected for the resident to have a manuscript prepared for journal submission shortly after the conclusion of the 16-week experience.

Preceptors served in traditional precepting roles tailored individually to the resident's previous experience and current performance and progression. In addition to these roles, preceptors served as co-authors on prepared manuscripts and as such performed the roles and responsibilities appropriate for authorship. ${ }^{12}$ The co-preceptors assisted with the conceptualization and design of reviews, data review and extraction, as well as writing, reviewing, and editing of manuscripts. ${ }^{12}$

\section{Resident Feedback}

Two residents completed the program in its first year. The two residents both identified increasing experience with manuscript writing and publishing as an opportunity for growth in their initial residency plan and selected this elective to help achieve this goal. After completion of the experience, they provided thoughtful feedback via evaluations in the residency learning system. Both the peer review and manuscript writing activities were well received, evident by comments included in the summative evaluations submitted by the residents:
"The opportunity to conduct a peer review and receive formal feedback on that review from preceptors was a very valuable activity. This helped me learn appropriate content of feedback as well as enhance my phrasing in feedback provided."
"I greatly appreciated the dedicated writing time from this rotation and would recommend future residents complete this rotation if writing and/or academia is important to their career goals." 
"While I have written two manuscripts for previous research projects, it was of added benefit to continue writing and receiving feedback on my writing for this piece... I had a significant amount of autonomy with this project, which allowed me to self-reflect on my growth and ask my preceptors specific questions [as needed]..."

This elective was unique from required longitudinal research, which also included preparation of a manuscript, as the primary focus of this elective experience was creation of medical writing and literature evaluation, while the research project focused more on study design and institutional review board protocol preparation. Thus, the residents reported that the experience did not feel redundant. Instead, they cited better preparation for the written work necessary in longitudinal research due to the elective experience.

\section{Critical Analysis}

The most tangible benefit of a medical writing experience is the scholarly output though this is certainly not the only, nor likely most significant, advantage. After the first year of offering this elective, two articles are in press. As such, this rotation has served as an effective launching pad for knowledge dissemination related to the residents' practice and interests.

Sharing knowledge and experience and increasing one's scholarly record are of vital importance; however, likely the most long-lasting benefit of this experience is the personal and professional growth achieved by both residents. Benefits from completing the medical writing elective early in the PGY-2 year proved meaningful later in residency training. While working with residents who completed this elective, other preceptors and the RPD provided feedback that they seemed better able and more confident to conquer other writing opportunities throughout the year, requiring less direct oversight and prompting from preceptors, compared to prior residents.

This elective proved mutually beneficial for preceptors and residents, since preceptors also increased scholarly output from the precepting experience. Additionally, given that preceptor development is an important part of every residency program, ${ }^{2}$ this elective encourages and supports continued preceptor growth and development in the area of writing and publication.

In contrast to a previously published residency writing program executed as a residency project, ${ }^{9}$ this medical writing experience was intentionally designed as a learning experience integrated into the year-long schedule and therefore assigned protected time and concentrated effort early in the year.

This elective was not without challenges. The main hurdle experienced by residents and preceptors was time management. The attempted solution was to create a welldefined timeline for completion of key steps within the medical writing process (Table 2). These steps for the resident's systematic review included topic selection, article selection review, first manuscript draft, final manuscript draft, and submission preparation. In regard to final article submission, the date for article submission was not established at the beginning of the elective, but instead discussed after the first manuscript draft was completed and adjusted as necessary. Another time-related barrier included the high demand of the two preceptors to provide meaningful and timely feedback for two resident writing pieces within a similar timeframe.

Variations in resident knowledge of and interest level in medical writing is another potential barrier. One resident had previous publication experience, while the other resident had none. This may reflect a common occurrence in experiences like this one, as residents frequently have different strengths, areas for improvement, and experiences. Therefore, individualized plans were created and adjusted to meet the unique needs of each participating resident.

Other minor challenges included providing a timely peer review experience and topic selection that allowed completion within the residency year. To conquer topic selection, discussion between preceptors and residents focused on areas of innovative pharmacy practices, future areas of practice, and new drug approvals that aligned with the resident's pharmacy areas of interest. Additionally, both preceptors serve as peer reviewers for multiple pharmacy journals. However, the peer review activities for the residents were limited by the availability of articles during the elective months.

\section{Next Steps}

To further improve this elective experience, the residents recommended providing more information on methods for becoming a peer reviewer for journals, other than through invitations from journals, and methods for connecting with editors. This would enhance the peer review activity by setting the residents up with avenues to continue to provide peer reviews in their future careers. Additionally, it was recommended to incorporate structured topic discussions, such as biostatistics, and research design. These topics support the learning experience of the elective, assist the residents with preparation for Board of Pharmacy Specialties ${ }^{\circledR}$ examinations, and contribute to their overall career goals.

In terms of integrating or creating a similar experience in other residency programs, the authors recommend a similar formula of co-preceptorship, motivated residents (thus the elective nature), and longitudinal design. Modification of this basic structure may be needed to accommodate the resources of a particular institution and the types of writing desired. The experience may be more reproducible with a consistent article- 
type requirement; however, that may restrict opportunities for the residents.

Challenges to successful implementation may be more commonly seen in PGY-1 programs, as residents may be less experienced and operate with less practice-area focus. While the ASHP PGY-2 competencies include elective goals related to publishing, the PGY-1 competencies do not, again suggesting best fit for this elective within a PGY-2 program. ${ }^{2,13}$

\section{CONCLUSION}

A unique longitudinal medical writing experience was created and executed in a PGY-2 residency program in response to the ever-growing need to publish and to continue to align training and learning experiences with accreditation standards, the evolution of the career expectations, and medical, pharmacy, and learning community needs. This rotation had many benefits, such as the scholarly output, resident development, and mutual support of preceptor and program goals. However, it was not without its challenges and opportunities, namely time. Moving forward, it is recommended that programs contemplating ways to enhance scholarly work consider implementing a similar medical writing experience tailored to the program, residents, and existing experience among preceptors.

Conflicts of Interest: None

Funding/support: None

\section{REFERENCES}

1. Moosa, I. A. (2018). "Publish or perish: Origin and perceived benefits". In Publish or Perish Perceived Benefits versus Unintended Consequences. Cheltenham, UK: Edward Elgar Publishing. doi: 10.4337/9781786434937.00007.

2. ASHP Commission on Credentialing. Competency areas, goals, and objectives for a residency in an advanced areas of pharmacy practice. American Society of Health-System Pharmacists. January 2018. https://www.ashp.org/-/media/assets/professionaldevelopment/residencies/docs/pgy2-outcomesgoals-objectives-residencies-advancedarea. ash $x$ ?la=en\&hash $=46$ DE9F61D2C2FB8442B07ED 75D136A8CA82778C8. Accessed November 8, 2019.

3. Stranges PM, Vouri SM. The impact of resident research publication on early-career publication success. Am J Health-Syst Pharm. 2016;73(12):895900. doi: 10.2146/ajhp150567.

4. Evans R, Miller Quidley A, Blake EW, et al. Pharmacy resident research publication rates; $A$ national and regional comparison. Curr Pharm Teach Learn. 2015;7:787-793. doi: 10.1016/j.cptl.2015.08.005.
5. Weathers T, Ercek K, Unni EJ. PGY1 resident research projects: Publication rates, project completion policies, perceived values, and barriers. Curr Pharm Teach Learn. 2019;11(6):547-556. doi: 10.1016/j.cptl.2019.02.017.

6. Cabanas G, Bridgeman MB, Hermes-DeSantis ER. Publish or perish: Success with publication in pharmacy residency training. Curr Pharm Teach Learn. 2018;10:1647-1651. doi: 10.1016/j.cptl.2018.08.017.

7. Bookstaver PB, Felder TM, Quidlet AM, Ragucci K, Nappi J, Draper HM. Pharmacy residents' barriers to scholarly pursuits. Curr Pharm Teach Learn. 2015;7:40-46. doi: 10.1016/j.cptl.2014.09.003.

8. Swanson JM, Shafeeq H, Hammond DA, Li C, Devlin JW. Association between postgraduate year 2 residency program characteristics and primary project publication. Am J Health-Syst Pharm. 2018;75:384-391. doi: 10.2146/ajhp160989.

9. Clemmons AB, Hoge SC, Cribb A, Masasco KB. Development and implementation of a writing program to improve resident authorship rates. Am J Health-Syst Pharm. 2015;72(suppl 2):S53-57. doi: 10.2146/ajhp150159.

10. Liberati A, Altman DG, Tetzlaff J, et al. The PRISMA statement for reporting systematic reviews and metaanalyses of studies that evaluate healthcare interventions: explanation and elaboration. BMJ. 2009;339. doi: 10.1136/bmj.b2700.

11. Ouzzani M, Hammady H, Fedorowicz Z, Elmagarmid A. Rayyan - a web and mobile app for systematic reviews. Syst Rev. 2016;5(1):210. doi: 10.1186/s13643-016-0384-4.

12. International Committee of Medical Journal Editors. Defining the Role of Authors and Contributors. http://www.icmje.org/recommendations/browse/rol es-and-responsibilities/defining-the-role-of-authorsand-contributors.html. 2019. Accessed September 9, 2019.

13. ASHP Commission on Credentialing. Competency areas, goals, and objectives for postgraduate year one (PGY1) pharmacy residencies. American Society of Health-System Pharmacists. March 2015. https://www.ashp.org/-/media/assets/professionaldevelopment/residencies/docs/requiredcompetency-areas-goals-objectives. Accessed September 16, 2019. 
Table 1. ASHP residency goals and objectives with associated writing rotation activities

\begin{tabular}{|c|c|c|c|}
\hline Goals & Objectives & $\begin{array}{l}\text { Taught }(T) \text { or } \\
\text { Evaluated (E) }\end{array}$ & Activities \\
\hline \multirow[t]{5}{*}{$\begin{array}{l}\text { R2.2 - Demonstrate } \\
\text { ability to conduct a } \\
\text { quality improvement } \\
\text { or research project in } \\
\text { the advanced practice } \\
\text { area }\end{array}$} & $\begin{array}{l}2.2 .1 \text { - (Analyzing) } \\
\text { Identify a scholarly } \\
\text { question related to } \\
\text { clinical practice, } \\
\text { education, or } \\
\text { healthcare that would } \\
\text { be useful to study and } \\
\text { can be completed } \\
\text { within the PGY2 } \\
\text { residency year }\end{array}$ & $\mathrm{T} / \mathrm{E}$ & $\begin{array}{l}\text { - Selection of a medical writing } \\
\text { project based on resident-specific } \\
\text { interests }\end{array}$ \\
\hline & $\begin{array}{l}2.2 .2 \text { - (Creating) } \\
\text { Develop a plan or } \\
\text { research protocol for } \\
\text { the project }\end{array}$ & $\mathrm{T} / \mathrm{E}^{\mathrm{A}}$ & $\begin{array}{l}\text { - Identify a journal for submission } \\
\text { - Develop research methods for } \\
\text { project }\end{array}$ \\
\hline & $\begin{array}{l}2.2 .3 \text { - (Evaluating) } \\
\text { Collect and evaluate } \\
\text { data for the project }\end{array}$ & $\mathrm{T} / \mathrm{E}^{\mathrm{A}}$ & $\begin{array}{l}\text { - } \quad \text { Evaluate a manuscript and } \\
\text { methodology quality (peer review) } \\
\text { - Screen and collect data with high } \\
\text { quality methods (writing project) }\end{array}$ \\
\hline & $\begin{array}{l}2.2 .5 \text { - (Evaluating) } \\
\text { Assess changes or need } \\
\text { to make changes based } \\
\text { on the project }\end{array}$ & $\mathrm{T}$ & $\begin{array}{l}\text { - Create thoughtful and appropriate } \\
\text { conclusions (systematic reviews) } \\
\text { - } \quad \text { Provide meaningful feedback to } \\
\text { authors (peer review) }\end{array}$ \\
\hline & $\begin{array}{l}2.2 .6 \text { - (Creating) } \\
\text { Effectively develop and } \\
\text { present, orally and in } \\
\text { writing, a final project } \\
\text { suitable for publication }\end{array}$ & $\mathrm{T} / \mathrm{E}$ & $\begin{array}{l}\text { - Develop a manuscript appropriate } \\
\text { for publication }\end{array}$ \\
\hline $\begin{array}{l}\text { R3.1 - Demonstrate } \\
\text { leadership skills }\end{array}$ & $\begin{array}{l}\text { 3.1.1 - (Applying) } \\
\text { Demonstrate personal, } \\
\text { interpersonal, and } \\
\text { teamwork skills critical } \\
\text { for effective leadership }\end{array}$ & $\mathrm{T} / \mathrm{E}$ & $\begin{array}{l}\text { - Serve as primary and } \\
\text { corresponding author on } \\
\text { publication } \\
\text { - Effectively manage work with } \\
\text { other contributors }\end{array}$ \\
\hline $\begin{array}{l}\text { R4.1 - Effectively } \\
\text { employs appropriate } \\
\text { preceptors' roles when } \\
\text { engaged in teaching }\end{array}$ & $\begin{array}{l}4.1 .3 \text { - (Applying) Use } \\
\text { effective written } \\
\text { communication to } \\
\text { disseminate knowledge } \\
\text { related to ambulatory } \\
\text { care }\end{array}$ & $\mathrm{T} / \mathrm{E}$ & $\begin{array}{l}\text { - Provide clear, concise, and } \\
\text { thoughtful feedback (peer review) } \\
\text { Develop a manuscript and cover } \\
\text { letter for submission to identified } \\
\text { journal }\end{array}$ \\
\hline
\end{tabular}

${ }^{\mathrm{A} A d d e d}$ evaluation after first year 
Table 2. Sample resident schedule

\begin{tabular}{cl}
\hline Week & \multicolumn{1}{c}{ Activity/Meetings } \\
\hline 1 & Discuss rotation, review syllabus ${ }^{\mathrm{A}}$ \\
\hline 2 & Meet to discuss peer review, research ideas $^{\mathrm{A}}$ \\
\hline 3 & Independent work - develop writing plan \\
\hline 5 & Meet to review writing plan $^{\mathrm{A}}$ \\
\hline 6 & Independent work - finalize writing plan \\
\hline 7 & Data collection/article search \\
\hline 8 & Data collection/article search \\
\hline 9 & Meet for rough draft/article selection review ${ }^{\mathrm{A}}$ \\
\hline 10 & Independent work - writing \\
\hline 12 & Independent work - writing \\
\hline 13 & Independent work - writing: draft due \\
\hline 14 & Meet to review draft ${ }^{\mathrm{A}}$ \\
\hline 15 & Independent work - writing \\
\hline 16 & Independent work - writing \\
\hline $17+$ & Final Meeting - article submission ${ }^{\mathrm{A}}$ \\
\hline
\end{tabular}

\footnotetext{
${ }^{A}$ Required meeting with resident and at least one preceptor
} 